\title{
Open Access, Open Science, Open Society
}

\author{
Thomas MARGONI ${ }^{\mathrm{a}, 1}$, Roberto CASO ${ }^{\mathrm{b}}$, Rossana DUCATO ${ }^{\mathrm{b}}$, Paolo GUARDA $^{\mathrm{b}}$, and \\ Valentina MOSCON ${ }^{\mathrm{b}}$ \\ ${ }^{\text {a }}$ School of Law - University of Stirling \\ ${ }^{\mathrm{b}}$ Faculty of Law - LawTech Group - University of Trento
}

\begin{abstract}
Open Access' main goal is not the subversion of publishers' role as driving actors in an oligopolistic market characterized by reduced competition and higher prices. OA's main function is to be found somewhere else, namely in the ability to subvert the power to control science's governance and its future directions (Open Science), a power that is more often found within the academic institutions rather than outside. By decentralizing and opening-up not just the way in which scholarship is published but also the way in which it is assessed, OA removes the barriers that helped turn science into an intellectual oligopoly even before an economic one. The goal of this paper is to demonstrate that Open Access is a key enabler of Open Science, which in turn will lead to a more Open Society. Furthermore, the paper argues that while legislative interventions play an important role in the top-down regulation of Open Access, legislators currently lack an informed and systematic vision on the role of Open Access in science and society. In this historical phase, other complementary forms of intervention (bottom-up) appear much more "informed" and effective. This paper, which intends to set the stage for future research, identifies a few pieces of the puzzle: the relationship between formal and informal norms in the field of Open Science and how this impact on intellectual property rights, the protection of personal data, the assessment of science and the technology employed for the communication of science.
\end{abstract}

Keywords. Open Science - Open Access - Intellectual Property - Copyright Privacy and Data Protection - Law and Technology - Comparative Law

\section{Open Access, Science and Society}

Open Access (OA) is a term that in recent years has acquired popularity and widespread recognition (Willinsky, 2006; Suber, 2012; Frosio 2014). International definitions and scholarly analysis converge on OA main characteristics: free availability on the public internet, permission to any users to read, download, copy, distribute, print, search, or link to the full texts of these articles, crawl them for indexing, pass them as data to software, or use them for any other lawful purpose, without financial, legal, or technical barriers other than those inseparable from gaining access to the internet itself. The only constraint on reproduction and distribution, and the only role for copyright in this domain, should be to give authors control over the integrity of their work and the right to be properly acknowledged and cited (BOAI, 2002; Bethesda Statement on OA, 2003; Berlin Declaration on OA, 2003). Suber defines OA as digital, online, free of charge, and free of most copyright and licensing restrictions. (Suber, 2012). However, while OA main features appear more or less

\footnotetext{
${ }^{1}$ Corresponding Author: thomas.margoni@stir.ac.uk
} 
known to many, its real function is often overlooked (Guédon, 2001). Open Access' main goal is not the subversion of publishers' role as driving actors in an oligopolistic market characterised by reduced competition and higher prices. Of course, an open and competitive market should certainly be seen with favour by economists and also by the community of scholars and the society at large, as this is usually synonym of faster innovation and better conditions for consumers --a larger consumer surplus, economists would say (Shavell, 2010; Ramello, 2011). Nevertheless, OA's main function is to be found somewhere else, namely in the ability to subvert the power to control science's governance and its future directions, a power that is more often found within the academic institutions rather than outside. By decentralising and opening-up not just the way in which scholarship is published but also the way in which it is assessed, OA removes the barriers that helped turn science into an intellectual oligopoly even before an economic one.

What is more, science is not only a key component of many social organisations, but can be seen as a form of social organisation in its own right (Merton, 1942; Polanyi, 1962). Therefore, changing those mechanisms that have explicitly or implicitly governed science and scientific institutions over the last few decades towards a more transparent and accountable model, will contribute to advance science in a more open, collaborative, democratic, and transparent system. This will in turn contribute to reach a more open, collaborative and transparent society (Bucchi, 2004). Consequently, the main argument presented in this paper, which sets the stage for future work, is that OA is not just an academic or scientific phenomenon, but is one that affects science in general and therefore society. Stronger Open Access will empower a thriving Open Science, which will enable a wealthier Open Society (Fecher and Friesike, 2013).

This thesis is followed by a logic corollary. Precisely within the rules and dynamics of a more open paradigm for science and society can be found the normative guidance that can help to reform the tools that regulate academic and scientific outputs: intellectual property, privacy and data protection, rules on scientific assessment and the role of technology.

The scope of this paper is limited to only some of the pieces of this intricate puzzle and accordingly attention is paid only to some of the legal aspects of Open Science policy: legislation on Open Access, Text and Data Mining and data protection.

The structure of the paper is as follows. After this general introduction (1), the main function of $\mathrm{OA}$ will be discussed under the assumption that $\mathrm{OA}$ is not only about scientific publications. On the contrary, the promotion of a model based on the wide availability of knowledge and on a decentralised system of scientific assessment will directly impact the way we imagine not only science but society in general (2). This theoretical analysis is followed by a survey of the main legislative and policy initiatives and by a brief discussion of how these initiatives have contributed (or not) to the achievement of OA/OS goals (3). New areas of scientific analysis where OA principles are in high demand such as in the field of data and databases will be presented in relation to Text and Data Mining (4), as well as in relation to the creation and use of databases and the dissemination of results containing personal data (5). In the last chapter brief conclusions and future work are identified (6). 


\section{Open Science: the unfinished revolution}

Open Science - i.e. the abstraction and general implementation of basic OA principles such as sharing, cooperation, democracy and transparency to the entire scientific field - is an unfinished revolution. Despite a large consent on the benefits of Open Science (OS) in terms of progress of knowledge, innovation, pluralism, transparency and preservation, the most part of scientific results and publications is under the "control" of traditional closed access publishers who base their business models on vast commercial databases protected by intellectual property (IP), contracts and technological protection measures (Björk, 2013).

Moreover, the oligopolistic power of commercial publishers is much stronger than before the digital age (Larivière et al., 2015). The most important reason for the marginal impact in quantitative terms of OS is likely linked to the phenomenon of commodification of scientific and academic research, which has characterised the last forty years (Radder, 2010). However, shaping scientific and academic research on pure market logics has many side effects. Amongst the most relevant is conceiving competition as a value in itself. For example the "publish or perish" logic, strengthened by bibliometrics, imposes on scientists a mentality shift that often privileges quantity and impact factor over quality and impact on society. According to this logic, publications are no longer expressions of critical thinking but commercial "products" (Pievatolo, 2015). Naturally, this form of hyper-competitive science reflects a system of power: referees, members of editorial boards, learned societies, commercial publishers and bibliometrics databases (e.g., ISI Web of Science and Scopus), universities, national agencies for quality assurance in higher education; all act under the control or at least the influence of the same market logic that sees science as a product. To illustrate this point with one example ex pluris, we can look at the fact that often the scientific achievements of a department are assessed also in the light of the number of patents that the department was able to secure. This is done on the assumption that more patents are always synonym of more or better innovation. While in many cases this is certainly true, a large amount of literature is emerging which demonstrates that there are extreme variations in the correctness of this assumption depending not only on the scientific field but also on the nature and structure of the patentee (Lemley, 2008). The main problem here is that the equation "more-patentsmore-innovation" was applied to the academic field in total absence of any sound analysis of the economic and funding structure of these institutions, nor was it supported by any serious empirical data. This is a direct effect of assuming - i.e. not proving - that a pure market system of incentives would work smoothly in the field of scientific and academic research, which is only partially moved by market incentives. As a result, many university patents are not effectively used, representing a cost for the institution and a barrier for other researchers.

As a matter of fact, science is not only a competitive game, it is also, sometime mostly, a collaborative one, where standard market incentives are only partially valued. In particular, OS is essentially based on collaborative action. In an OS model, the Mertonian norms of "communalism", "disinterestedness" and "organised scepticisms" are not only present "by design" but also enhanced by digital technologies. Illustratively, institutional and disciplinary OA repositories based on a common interoperable standard (Open Access Initiative-Public Metadata Harvesting) feature a great example of the interaction between the Mertonian scientific norms and the use of technology. 
Until recently, OS has been driven by a bottom-up approach based on technological infrastructures and solemn declarations such as Budapest, Bethesda and Berlin declarations; but in the last years we are facing a new top-down approach based on legislative tools (de Roman Perez, 2012; Caso, 2013; Moscon, 2015b; Guibault, 2015a, 2015b; Visser 2015; Todolí Signes, 2015; see paragraph 3). This mix of bottomup and top-down initiatives can be particularly effective. Nevertheless, especially in the case of top-down initiatives, legislators have often showed a lack of systematic view, which caused their interventions to lack real effectiveness. If we want to make science really open we have to study with more attention the interaction between social norms (and ethics), legal rules and technology. Without a new scientific thrust centred on cooperation, OS will remain an unfinished revolution. From this perspective we have to deeply rethink IP and copyright (Reichman, Okediji, 2012), the assessment and the technological infrastructures of science. Furthermore, we also need to rethink the education of scientists and lawyers putting at the centre of undergraduate and $\mathrm{PhD}$ programs a critical perspective on IP, assessment of science and technology. Mertonian CUDOS can be seen as a set of normative elements - already clearly present in $\mathrm{OA}$ - where to start from.

\section{Open Access legislative and policy interventions}

Recent empirical studies have shown that the implementation of OA policies varies by country and discipline (Migheli and Ramello, 2014; Eger et al., 2013). While one of the difficulties in unfolding the full potential of OA can be found in the hostility found in traditional publishers towards the OA paradigm, obstacles to OA publishing are present within the scientific community itself. This is largely due to the aforementioned commodification phenomenon (Radder, 2010).

A bottom-up approach based on ethical rules and social norms is likely the key element in guaranteeing success and future viability to OA (Lametti 2010; Geiger, 2013). However, a top-down complementary intervention may play an equally important role in addressing cultural and social change towards a broad dissemination of, and access to, research outputs (Reichman and Okediji, 2012; Priest, 2012). Within top-down approaches we can distinguish between institutional policies and legislative interventions. Institutional policies are adopted by research and funding bodies in accordance with organisational and regulatory choices and are crucial in promoting OA. Various options have emerged and prima facie institutional policies can be grouped into two main categories: voluntary and mandatory (Suber, 2012). The first category provides recommendations encouraging university departments to publish or re-publish in OA according to the gold or green road (Harnad et al., 2004)

Mandatory policies require the publication in OA following the green or gold road. In particular, the gold road may be more problematic as it is usually costly, requiring the payment of Article Processing Charge (APC), at least when Gold OA is combined with an author's pays business model. A distortion of this model is emerging as hybrid OA publishing, that is to say, traditional journals that offer the author of a given article the possibility to "buy back" the right to OA (Adams, 2007; Bjork, 2012).

In legal systems that encourage publication in gold OA such as the UK the institutional policies provide for specific funding mechanisms for OA publications. Gold OA funding was recently discussed at the Berlin Conference on the 
reorganisation of funding models for scholarly journals ${ }^{2}$. A process was initiated there to transform subscription journals into Open Access. The key element in this discussion is strictly connected with the scientific institutions and their sponsors' policies: public resources that are currently spent on journal subscriptions could be converted into open-access publishing funds with clear savings for Universities libraries.

Yet, mandatory green OA institutional policies are subordinated to the author's ownership of copyright. Given the weakness of the author in the contractual bargaining with publishers (especially when the author has to publish in specific high impact journals for assessment purposes) often authors will have transferred the right to (OA) publish. An example of an extra EU policy that found a solution to this problem can be seen in the model adopted by Harvard University. Harvard's OA policy introduced a legal mechanism through which, at the start of the publishing process, the university is automatically considered the non-exclusive licensee of the right to archive and publicly distribute all faculty-produced scholarly articles (Priest, 2012).

Moving the analysis to legislative interventions, some European governments have taken steps towards proper recognition of OA principles through the approval of specific Acts (i.e. Spain, Artículo 37 "Difusión en acceso abierto", Ley 14/2011, de 1 de junio, de la Ciencia, la Tecnología y la Innovación; Italy, § 4, Law October 7 2013, no. 112; Germany, Law October 12013 (BGB1. I S. 3714) amending Article 38 Copyright Act; Netherlands, Law June 30, no. 257 amending Article 25 fa Copyright Act). Since 2006, the European Commission favours OA to publications and scientific data. The EU Commission requires that research funded by at least $50 \%$ with its money (i.e. FP7 and Horizon 2020 framework programs) be published in OA and has recently developed a pilot that covers also data. The EU also encourages Member States to take measures aimed at promoting Open Access as witnessed by the EU Communication "Towards better access to scientific information: Boosting the benefits of public investments in research" COM (2012) 401, and by the Commission Recommendation on "Access to and preservation of scientific information" (2012/417/EU) of 17 July 2012. The European approach promotes a multilayer system involving lawmakers, national legislatures, funding bodies and research entities that manage public funds.

Interesting national implementations can be seen in Spain where the legislature implemented Art. 37 (Difusión en acceso abierto) of Law 14/2011, of 1st of June "de la Ciencia, la Tecnología y la Innovación" (de Roman Perez, 2012; Todolí Signes, 2015). The scope of the rule is limited to serial or periodical publications and requires research that is more than $50 \%$ state-funded to be published as soon as possible - no later than 12 months after the first publication - in the form of the final version accepted for publication in an open-access disciplinary or institutional repository (Green Road). It is worth mentioning that the version of the publication which is republished in open- access repositories is available for consideration in the evaluation procedures of public administration. The main limit of this provision is that it explicitly - does not override agreements that transfer to third parties the rights on the publication. A similar approach was adopted by the Italian legislature in Law of 7 October 2013, n. 112, G.U. n. 236, 8.10.2013). The Act seeks to bring Italian law in line with the aforementioned EU Recommendation, by requiring that all the subjects involved "implement the necessary measures for the promotion of Open Access" with regard to works publicly funded (at least 50\%) and published in periodical collections

${ }^{2}$ http://openaccess.mpg.de/Berlin-Conferences 
(at least biannually). The new Act requires research institutions to adopt policies that promote OA by following both the gold road and the green road. Similarly to the Spanish example, the new Italian law does not address the issue of IP rights. Consequently, authors may find themselves in the need of assigning their copyright thereby losing the power to determine how their research will be published (Caso, 2013; Moscon 2015b).

A completely different approach can be seen in the "German model" which was source of inspiration also to the Dutch Legislator (Guibault, 2015a; 2015b; Visser, 2015). The Law of 1 October 2013, amending Section 38 of the German Copyright Act (Urheberrechtsgesetz-UrhG) aims to remove one of the main obstacles to OA, i.e. the loss of the right to republish the work as a consequence of assigning the copyright to the publisher. The new law allows the author of a scientific work, published in a periodical collection (at least biannually) and created in the context of a research activity that "was at least $50 \%$ publicly funded", to make his work publicly available for non-commercial purposes 12 months after the publication. The provision is mandatory and cannot be limited by contract. Whether rules on conflict of laws, i.e. to say whether a publishing agreement between a publisher and an author which contains a choice of law provision excluding the applicability of the national OA provision, can constitute a quick and viable circumvention of said provision is not certain; But this hardly could have been the intention of the legislator (Guibault, 2015b).

\section{Open Access, Text and Data Mining and the benefits for science and society}

Text and Data Mining (TDM) is the process of extracting (new) information from newly created or already existing knowledge. The process of information extraction is performed using automated statistical analysis tools. In particular, TDM is emerging as a powerful tool "for harnessing the power in data by analysing datasets and content at multiple levels" in order to discover concepts and entities in the world, patterns they may follow and relations they engage and on this basis annotate, index, classify and visualise such content (OpenMinTeD, 2015). From a legal standpoint, it is important to note that these datasets and content (e.g. data, alphabetic or numerical entries, texts, articles, papers, collections of words such as vocabularies and corpora, databases) can receive different types of protection. Firstly, there is copyright, usually protecting the single elements of the database when these are original works of authorship (e.g. scientific papers, drawings, images). Secondly, the sui generis database right (SGDR) on databases that were made thanks to a "substantial investment" (Bently and Sherman, 2014; Derclaye, 2008; Wiebe and Guibault, 2013). As a matter of fact, copyright could also protect the database as such, but this is only possible when the database structure (the selection or arrangement of contents) is original in the sense of the author's own intellectual creation. This latter situation is not common for many databases in the scientific field and more importantly the scope of protection only extends to the structure of the database and not to its content. Therefore, for the purpose of most, if not all, TDM activities this form of protection is not relevant. What can represent a real barrier to TDM are the two other forms of protection: copyright on the elements of the database and the SGDR on the database itself (Guibault and Margoni, 2015).

Copyright on the elements of a database (DB): copyright protects works of authorship such as scientific, literary or artistic works. Therefore, when a DB is composed by journal articles, original photographs, musical compositions, etc. these 
will most likely be protected by copyright. Other items such as sound recordings, non original photographs (only in some cases), broadcasts, performances, fixations of films (e.g. the audiovisual recordings of birds hatching in their natural environment) can constitute protected subject matter even though technically speaking these do not constitute works protected by copyright, but "other subject matter" protected by rights related to copyright, also known as neighbouring rights. Copyright prevents acts such as making copies (total or partial, permanent of temporal) and redistribution of those copies in verbatim or modified form in absence of authorisation. Neighbouring rights offer similar, though not identical, protection.

The SGDR is a peculiar EU form of protection for databases which are protected regardless of any originality. What is protected is the "substantial investment" in quantitative or qualitative terms that the maker of the database puts in it. This substantial investment can take the form of time, money, labour or any other resources spent in the making of a DB. Importantly, when talking about "making" the database, the substantial investment has to be in the obtaining, verification and presentation of the data and not in their creation (Hugenholtz and Davison, 2005). The extent to which scientific databases can be said to be constituted by created or obtained data is not clearly settled in case law. In particular, the dichotomy between creating and obtaining data is not necessarily solved at the epistemological level.

TDM often, if not always, requires the making of a usually temporal copy of the datasets or works to be mined. The EU legal framework sketched above has been drafted in an era when methods such as TDM were unknown. However, said framework is based on the assumption that authors deserve a high level of protection (InfoSoc Directive, Recital 9) which has led to the formulation of very broad definitions of protected rights (e.g. the right of reproduction regulated in Art. 2 InfoSoc) and to the creation of special rights such as the SGDR. On the contrary, the set of rules intended to balance this exclusivity has been drafted in very loose terms and accordingly exception and limitations to copyright and to the SGDR are exhaustively listed in the InfoSoc and Database directive, but are not made mandatory (except for Art. 5.1 InfoSoc). The resulting situation, which has been referred to as an "accident" (Copyright Society Opinion 2014), is one were, at least in the EU, TDM is an act that most likely infringes copyright and/or the SGDR, absent a specific nationally implemented exception (to date only the UK has created a TDM exception limited to non-commercial purposes). Contrast this situation to countries such as the US, where TDM and web-mining have been held to be a transformative use covered by fair use (Authors Guild, Inc. v. Google Inc., 954 F. Supp. 2D 282 (S.D.N.Y. 2013), Aff d $20152 \mathrm{~d}$ Circuit). Other countries such as Japan have likewise clarified the legitimacy of this technology (Guibault and Margoni 2015). Unfortunately, the EU, despite general declarations, seems to be falling behind in this strategical field of science and technology.

Consequently, given the likely - but not certain - presence of the aforementioned forms of protection, content and databases to be TDM have to be licensed under licenses capable of addressing the identified rights. In fact, when those rights are present, the default situation is that of "all rights reserved" and even if the database is publicly available on the Internet acts such as reproduction and distribution are not permitted, unless of course specific exceptions and limitations to copyright apply. Currently, most exceptions to copyright and to the SGDR under EU law are not fit to fully cover the needs of TDM. Furthermore, as it is known, of the 21 exceptions listed in Art. 5 InfoSoc only 1 is mandatory, while the remaining 20 are implemented at the 
discretion of each of the 28 European Member States. This situation is clearly unsatisfactory in terms of legal certainty and even though some countries (such as the UK) have shown foresight by creating a dedicated TDM exception the presence of a non-commercial limitation still represents a competitive barrier if compared to other more dynamic legal systems (e.g. the US).

Licences such as the Creative Commons Public License (CCPL) version 4 are a technically viable alternative to the lack of proper legislative intervention in this field. CCPLv4 addresses both copyright and SGDR in the licensed work. In particular, by applying a CCPL 4.0 to a DB such as a website or a repository of journal articles the licensor (the person who applies the licence and who needs to be the right holder or be authorized by the right holder to do so) is giving permission to reuse: a) the SGDR in the database; b) copyright in the DB in the limited cases in which copyright applies to the DB structure; and c) copyright and/or related rights in the elements (works such as journal articles and original photographs) composing the DB.

While other open content licenses may also achieve the same results, the convergence towards one, or a few, licenses that can be seen as a de facto standard is not only desirable but also essential in order to lower the transitive costs associated with license compatibility and therefore to facilitate use and reuse of resources for goals such as TDM.

\section{Open Science and Data Protection: specific v. any purpose?}

To facilitate the appropriate understanding and study of OS, it is crucial to take into account the rules stated by data protection regulations: a research study, a scientific paper or any product of scientific investigation (i.e., databases, slides, blog, etc.) may contain personal (i.e. any information relating to an identified or identifiable natural person) or even sensitive (i.e. data revealing racial or ethnic origin, political opinions, religious or philosophical beliefs, trade-union membership, and the processing of data concerning health or sex life) information.

In the field of data protection, the European reference framework is that of Article 8 of the Chart of Fundamental Right of the EU (recognizing the protection of personal data as an autonomous fundamental right) Article 16 of the TFEU (Treaty on the Functioning of the European Union), and Directive 95/46/EC (Data Protection Directive, hereinafter: DP Directive) (Bygrave, 2014) ${ }^{3}$. As known, a General Data Protection Regulation ("GDPR") has been recently approved and will replace the DP Directive, updating the European privacy rules to the digital era and overcoming the existing fragmentation in the application of data protection law across the EU member states (De Hert and Papakonstantinou, 2012) ${ }^{4}$.

For the purpose of this paper, we will take into account two phases in the data processing cycle. Firstly, the phase of collection and use of personal data. At this stage,

\footnotetext{
${ }^{3}$ Directive 95/46/EC of the European Parliament and of the Council of 24 October 1995 on the protection of individuals with regard to the processing of personal data and on the free movement of such data (Official Journal L 281,23/11/1995 p. 31 - 50). The European data protection framework is complemented by Directive 2002/58/EC on privacy and electronic communication.

${ }^{4}$ Pending the drafting of this paper, the European legislative process has arrived to its final stage. The agreement on the final text of the Regulation has been reached on December 2015, therefore any reference to the European Regulation in this paper shall be construed as referring to the consolidated text available at: http://static.ow.ly/docs/Regulation_consolidated_text_EN_47uW.pdf.
} 
the fundamental legal tool is formed by the combination of two concepts: consent (Article 7.a, DP Directive) and the information to be given to the data subject (Articles 10-11, DP Directive). In particular, the latter (in addition to the elements set out in Article 10) must indicate the purposes of the processing for which the data are intended, in conformity with the principle of the "specific purpose", within the meaning of Article 6.1.b, according to which data must be: " collected for specified, explicit and legitimate purposes and not further processed in a way incompatible with those purposes". Thus, at the time of recording personal data, the controller must obtain a specific and informed consent for the purposes for which the processing is intended. However, the DP Directive states a very important principle in our context by making a general presumption of compatibility of the research purposes with any previous processing: "Further processing of data for historical, statistical or scientific purposes shall not be considered as incompatible provided that Member States provide appropriate safeguards" (Article 6.1.b, DP Directive). This means that in case of "secondary uses" for research purposes, the processing is presumed to comply with the principles enshrined in the European legal framework. In this context national legislators shall furnish suitable safeguards. This setting is also confirmed in the GDPR (Recital 40).

The second important phase of the processing is represented by the dissemination of research results containing personal data. In this case as well, the detailed operational rules and procedures applicable are determined by the Member States, as established by DP Directive (Article 13.2). For example, according to Italian law, which explicitly recalls the recommendations of the Council of Europe ${ }^{5}$, research results shall be published or otherwise disseminated only as aggregate data or in ways that the data subject cannot be identified. Furthermore, sensitive data processed for research purposes has to be anonymised. The GDPR underlies the crucial role of research results, especially in the medical and life sciences field (see Recital 125aa). However, the provision regarding the processing of personal data for scientific, historical and statistical purposes has been radically changed during the trilogue's meetings. In the proposal made by the EU Commission in 2012, Article 83 contained a specific regulation on the publication of personal data for research purposes, while the consolidated text now entrusts the adoption of specific safeguards to Member States and Union law. Therefore, in this sensitive sector the unifying purpose of the Regulation is likely to have missed an important opportunity.

In the light of this investigation, the most interesting legal issue concerns the possible clash between the different purposes of the processing, on the one hand, and the circulation of content governed by an OA license, on the other hand. While in the privacy context the focus on the "specific purpose" principle of the processing forms the hub of the whole system of protection, the Open Access expressly stresses the ability to reuse data "for any purpose".

\footnotetext{
${ }^{5}$ Ex pluris, Council of Europe, Committee of Ministers, Recommendation No. R (83)10 on theprotection of personal data used for scientific research and statistics (Sept. 23, 1983); Recommendation No. R (92) 3 on genetic testing and screening for health care pursposes (Feb. 10, 1992); Recommendation No. R (97) 5 on the protection of medical data (Feb. 13, 1997); Recommendation No. R (97) 18 concerning the protection of personal data collected and processed for statistical purposes (Sept. 30, 1997).
} 


\section{Conclusions and future work}

The goal of this paper is to demonstrate the fundamental relation between Open Access, science and society. Not only OA can influence scientific and social institutions towards a more open and transparent model, but a more open paradigm in science and society can offer the normative guidance needed to adjust some of the basic rules that regulate the Information Society: intellectual property, the protection of personal data, the assessment of scientific and academic outputs and the role of technology. Furthermore, it emerged that while legislative interventions play an important role in the top-down regulation of Open Access, legislators currently lack a general and systematic vision of the role of Open Access in science and society. In this historical phase, other complementary forms of intervention (bottom-up) appear much more "informed" and effective. Legislative interventions mandating the green road or conferring an unalienable right of publication to the author are useful instruments but only partially effective. These top-down interventions must be combined with bottom- up solutions such as institutional policies that mandate green road archiving. A particularly well drafted example of this latter policy can be found in the French INRIA institutional policy that requires to deposit in the French OA archive HAL the results of research, establishing that only the deposited articles will be considered for assessment ${ }^{6}$.

Future work will investigate in more depth other pieces of the puzzle that this study has started to analyse. In particular, it is important to analyse the relationship that exists between formal rules and informal norms in the field of Open Science, intellectual property rules, personal data protection, the assessment and the communication of scientific and academic research.

\section{References}

Adams, A. (2007). Copyright and research: an archivangelist's perspective. SCRIPTED, 4(3), pp. 285-290.

Bently, L. and Sherman, B. (2014). Intellectual property law. Oxford: Oxford University Press.

Björk, B. (2013). Open Access-Are the Barriers to Change Receding?. Publications, 1(1).

Björk, B. (2012). The hybrid model for open access publication of scholarly articles: A failed experiment?. J Am Soc Inf Sci Tec, 63(8), pp.1496-1504.

Bucchi, M. (2004). Science in society. London: Routledge.

Budapestopenaccessinitiative.org, (2016). Budapest Open Access Initiative | Read the Budapest Open Access Initiative. [online] Available at: http:/www.budapestopenaccessinitiative.org/read [Accessed 3 Mar. $2016]$.

Bygrave, L. (2014). Data Privacy Law: An International Perspective. Oxford: OxfordUniversity Press.

Caso, R. (2013). La legge italiana sull'accesso aperto agli articoli scientifici: prime note comparatistiche. Il diritto dell'informazione e dell'informatica, 4, pp.681-702.

Derclaye, E. (2008). The legal protection of databases. Cheltenham, UK: Edward Elgar.

\footnotetext{
${ }^{6}$ https://iww.inria.fr/hal/aide/spip.php?article327\&lang=fr
} 
De Hert, P. and Papakonstantinou, V. (2012). The proposed data protection Regulation replacing Directive 95/46/EC: A sound system for the protection of individuals. Computer Law \& Security Review, 28(2), pp.130-142.

De Román Pérez, R. (2012). Acceso abierto a los resultados de investigación del profesorado universitario en la Ley de la Ciencia. Diario La Ley, (7986).

Eger, T., Scheufen, M. and Meierrieks, D. (2013). The Determinants of Open Access Publishing: Survey Evidence from Germany.

SSRN Electronic Journal.European Copyright Society, (2014). Answer to the EC Consultation on the review of the EU copyright rules. [online] Available at: https:/europeancopyrightsocietydotorg.files.wordpress.com/ 2015/12/ecs_answer_to_ec_consultation_on_copyright_review.pdf [Accessed 3 Mar. 2016].

Fecher, B. and Friesike, S. (2013). Open Science: One Term, Five Schools of Thought. [online] Dx.doi.org. Available at: http://dx.doi.org/10.2139/ssrn.2272036 [Accessed 3 Mar. 2016].

Frosio, G. (2014). Open Access Publishing: A Literature Review. SSRN Electronic Journal.

Geiger, C. (2013). The social function of intellectual property rights, or how ethics can influence the shape and use of IP law. In: G. Dinwoodie, ed., Intellectual Property Law: Methods and Perspectives, 1 st ed. Cheltenham: Edward Elgar, p.153.

Guédon, J. (2001). In oldenburg's long shadow. [Montreal]: Assoc Of Research.

Guibault, L. (2015a). Almost there! In Support of the Green Road to Dutch Science!. [Blog] Kluwer Copyright Blog. Available at: http://kluwercopyrightblog.com/2015/04/09/almost-there-in-support-of-thegreen-road-to-dutch-science/ [Accessed 3 Mar. 2016].

Guibault, L. (2015b). Back on the Green Road: How Imperative are Imperative Rules?. [Blog] Kluwer Copyright Blog. Available at: http://kluwercopyrightblog.com/2015/04/19/back-on-the-green-road-howimperative- are-imperative-rules/ [Accessed 3 Mar. 2016].

Guibault, L. and Margoni, T. (2015). Legal Aspects of Open Access to Publicly Funded Research. In: OECD, ed., Enquiries into Intellectual Property's Economic Impact, 1st ed. [online] Available at: http://www.oecd.org/sti/ieconomy/KBC2- IP.Final.pdf [Accessed 3 Mar. 2016].

Harnad, S., Brody, T., Vallières, F., Carr, L., Hitchcock, S., Gingras, Y., Oppenheim, C., Stamerjohanns, H. and Hilf, E. (2004). The Access/Impact Problem and the Green and Gold Roads to Open Access. Serials Review, 30(4), pp.310-314.

Hugenholtz, P. and Davison, M. (2005). Football fixtures, horseraces and spinoffs: the ECJ domesticates the database right. EIPR, 3, pp.113-118.

Lametti, D. (2010). How virtue ethics might help erase C-32's conceptual incoherence. In: M. Geist, ed., From "Radical Extremism" to "Balanced Copyright": Canadian Copyright and the Digital Agenda, 1st ed. Toronto: Irwin Law, p.309.

Larivière, V., Haustein, S. and Mongeon, P. (2015). The Oligopoly of Academic Publishers in the Digital Era. PLOS ONE, 10(6), p.e0127502.

Legacy.earlham.edu, (2016). Bethesda Statement on Open Access Publishing. [online] Available at: http://legacy.earlham.edu/ peters/fos/bethesda.htm [Accessed 3 Mar.2016].

Merton, R. (1942). Science and Technology in a Democratic Order. Journal of Legal and Polotical Sociology, 1, p.115.

Migheli, M. and Ramello, G. (2014). Open Access Journals \& Academicss Behaviour. SSRN Electronic Journal. 
Moscon, V. (2015a). University Knowledge Transfer: From Fundamental Rights to Open Access within International Law. In: G. Bellantuono and T. De Rezende Lara, ed., Law, Development and Innovation, 1st ed. Berlin: Springer, pp.147 - 189 .

Moscon, V. (2015b). Academic Freedom, Copyright, and Access to Scholarly Works: A Comparative Perspective. In: R. Caso and F. Giovanella, ed., Balancing Copyright Law in the Digital Age - Comparative Perspectives, 1st ed. Berlin: Springer, pp.99-135.

Openaccess.mpg.de, (2016). Berlin Declaration. [online] Available at: http://openaccess.mpg.de/ Berlin-Declaration [Accessed 3 Mar. 2016].

OpenMinTeD, (2016). Home - OpenMinTeD. [online] Available at: http://openminted.eu/ [Accessed 3 Mar. 2016].

Pievatolo, M. (2015). Publishing without perishing. Are there such things as "research products"?. In: Aisa 1st annual conference Nostra res agitur: open science as a social question.

Polanyi, M. (1962). The Republic of science. Minerva, 1(1), pp.54-73.

Priest, E. (2012). Copyright and the Harvard Open Access Mandate. Northwestern Journal of Technology and Intellectual Property, 10, p.377.

Radder, H. (2010). The commodification of academic research. Pittsburgh Pa.: University of Pittsburgh Press

Ramello, G. (2010). Copyright \& Endogenous Market Structure: A Glimpse from the Journal Publishing Market. Review of Economic Research on Copyright Issues, 7(1), pp.7 29

Reichman, H. and Okediji, R. (2012). When Copyright Law and Science Collide: Empowering Digitally Integrated Research Methods on a Global Scale. Minnesota Law Review, 96(4).

Shavell, S. (2010). Should Copyright of Academic Works be Abolished?. Journal of Legal Analysis, 2(1), pp.301-358.

Suber, P. (2012). Open access. Cambridge, Massachusetts: MIT Press.

Todolí Signes A. (2015). El open access en la regulación española, in J.A. Altès Tárrega, Investigación, docencia universitaria y derechos de propriedad intelectual, Tirant lo blanch, Valencia, 119.

Visser, D. (2015). The Open Access provision in Dutch copyright contract law. Journal of Intellectual Property Law \& Practice, 10(11), pp.872-878.

Wiebe, A. and Guibault, L. (2013). Safe to be open - Study on the protection of research data and recommendations for access and usage. Gottingen: Universitatsverlag.

Willinsky, J. (2006). The access principle. Cambridge, Mass.: MIT Press. 